\title{
Seismic Performance of Self-Centering Steel Plate Shear Walls with Beam-Only-Connected Web Plates
}

\author{
Patricia M. Clayton ${ }^{\mathrm{a}, 1, *}$, Jeffrey W. Berman ${ }^{\mathrm{b}, 2}$, Laura N. Lowes ${ }^{\mathrm{b}, 2}$ \\ ${ }^{a}$ Department of Civil, Architectural, and Environmental Engineering, University of Texas at \\ Austin, Stop C1700, Austin, TX, 78712, USA \\ ${ }^{b}$ Department of Civil and Environmental Engineering, University of Washington, Box \\ 352700, Seattle, WA, 98195, USA
}

\begin{abstract}
In the self-centering steel plate shear wall (SC-SPSW) system, thin steel web plates provide the primary lateral strength and energy dissipation, while posttensioned connections in the boundary frame provide recentering and mitigate frame damage. In most steel plate shear walls (SPSWs), web plates are connected to the beams and columns; however, connecting the web plates to the beams only has been proposed as a means of reducing boundary frame demands and mitigating web plate damage. This paper investigates the impact of using beam-only-connected web plates on SC-SPSW design and seismic performance. Expressions for determining beam demands for purposes of design are developed. Three- and nine-story prototype SC-SPSWs are designed using beam-onl-connected web plates and are compared with equivalent SC-SPSWs designs with fully-connected web plates. To evaluate the potential for material savings, the weight of steel required for each system is compared. The seismic performance of the SC-SPSWs with beam-only-connected and fully-connected web plates are compared using results of nonlinear response history analyses in which relatively simple, yet conservative, modeling techniques are employed.

Keywords: Self-centering, Post-tensioned connection, Steel plate shear wall,
\end{abstract}

\footnotetext{
* Corresponding author

Email addresses: clayton@utexas.edu ( Patricia M. Clayton), jwberman@uw.edu ( Jeffrey W. Berman), lowes@uw.edu ( Laura N. Lowes)

${ }^{1}$ Assistant Professor

${ }^{2}$ Associate Professor
} 
Numerical model, Seismic performance

\section{Introduction}

The self-centering steel plate shear wall (SC-SPSW) is a lateral force-resisting system that is capable of withstanding moderate to severe seismic events with full recentering capabilities and with damage concentrated in easily replaced thin steel infill plates, referred to as web plates $[1,2]$. The SC-SPSW utilizes web plates to provide the energy dissipation and primary lateral strength of the system, while the boundary frame employs post-tensioned (PT) beam-tocolumn connections to provide recentering and mitigate frame damage. Under lateral loading, beams rock about their flanges at the PT connection to form a gap $\left(\theta_{r}\right.$ in Fig. 1) between the decompressed beam flange and the column. The formation of this gap eliminates the plastic rotation that would have otherwise been present in a welded moment-resisting connection. Analytical design expressions and performance-based design methodologies have been developed to facilitate SC-SPSW design at the component and system level [1, 2]. The seismic performance of the SC-SPSW has been validated with nonlinear response history analyses of several prototype buildings [1] and with subassemblage and full-scale experiments $[3,4,5]$. These studies demonstrates the system's potential for reducing post-earthquake downtime and repair costs due to structural damage.

As with conventional steel plate shear walls (SPSWs), which employ web plates with boundary frames with welded moment-resisting connections, the web plates in SC-SPSWs resists lateral load through the development of tension field action (TFA) [6]. Under lateral loading, $V$, the TFA present in the web plate results in the distributed diagonal loads, $\omega$, acting on the boundary frame members at and angle $\alpha$, imposing both axial and lateral distributed loading on the beams and columns (Fig. 1). When columns are capacity designed to resist the expected yield strength of the web plate (as is suggested for conventional SPSWs [7] and for SC-SPSWs [1]), the required column sizes can be 
substantial. Potential methods for reducing column demands in SPSWs have been proposed, including offsetting web plates at each story [6], using outriggers or coupling beams to reduce overturning forces $[6,8]$, perforating web plates to reduce overstrength [9], and releasing the web plates from the columns [10, 11]. The latter option is of particular interest in SC-SPSW applications as discussed below.

Experimental and numerical investigations of single-story SPSWs with web plates connected to the beams only, referred to as beam-only-connected web plates, have shown the system to have significant lateral resistance, energy dissipation, and ductility $[10,11,12]$. Beam-only-connected web plates are particularly appealing for application in SC-SPSWs due to the phenomena of gap opening and frame expansion, which are particular to PT moment-resisting frames. As the PT connections rock open during lateral sway, the columns (with an original centerline spacing of $L$ ) are pushed apart due to the formation of the gap $\left(\Delta_{\text {gap }}\right.$ in Fig. 1). As a result, web plates in SC-SPSWs have two additional demands that are not present in conventional SPSWs where gap opening and frame expansion do not occur: (1) an additional net horizontal strain due to frame expansion and (2) localized strains near the rocking PT connections.

In SC-SPSWs, gap opening in the connections increases localized tensile strains in the web plate where the gap forms. Although corner cutouts are suggested (shown in Fig. 1) to accommodate gap opening and prevent web plate tensile rupture, the increased tensile strains in this region result in increased plastic elongation along the cutout. As the gap closes, the plastically elongated plate near the cutout must buckle out-of-plane. The out-of-plane deformation along the free edge produces large curvature demands at the edge of the bolted or welded web plate-to-boundary frame connection as shown in Fig. 2 for a full-scale SC-SPSW specimen with a welded web plate connection detail [5]. Experimental observations suggest that these localized out-of-plane deformations at the edge of the corner cutout are the primary cause of initiation of web plate tearing for tests with welded and bolted web plate-to-boundary frame connection details [4]. Note that this out-of-plane deformation is not typically 
present in conventional SPSWs, as the web plates are connected to the boundary frame along their entire edge and there is no beam-to-column connection rocking.

When the web plate is released from the columns, the additional horizontal strain associated with frame expansion is eliminated, as are the localized tensile strains near the opening PT connection (Fig. 8). The free edge of the beamonly-connected web plate will still deform out-of-plane due to shear buckling; however, the localized web plate curvature at the end of the bolted or welded web plate connection is significantly reduced. As a part of the large-scale twostory SC-SPSW subassembly test program presented in Clayton et al. [4], one specimen (W14-8s100k20GaHBE) employing beam-only-connected web plates was tested (shown in Fig. 8). When compared with a similar specimen (i.e. having the same web plate thickness, number of PT strands, initial PT force, and load protocol) with fully-connected web plates (i.e. connected to the beams and columns), the beam-only-connected web plate specimen achieved a significantly larger drift prior to the onset of web plate tearing and noteably less tearing at the end of testing at $5 \%$ drift [4].

Although beam-only-connected web plates offer the potential benefits of mitigating web plate damage and reducing column demands in SC-SPSWs, a possible drawback is their reduced lateral load capacity compared with fullyconnected web plates. Because the columns do not restrain the tension field in the entire web plate, beam-only-connected web plates develop only a partial tension field (Fig. 3) over the diagonal portion of the plate restrained by both boundary beams. The partial tension field (PTF) results in reduced lateral strength for a given web plate thickness and geometry compared with fully-connected web plates. To develop lateral strength comparable to a fullyconnected SC-SPSW, a SC-SPSW with beam-only-connected web plates must have thicker plates, wider or more numerous SC-SPSW bays, or a combination of these. The associated increase in material may impact the potential steel savings hoped to gain by using beam-only-connected web plates to reduce column demands; this is investigated as part of the current study. 
This paper discusses design considerations for SC-SPSWs employing beamonly-connected web plates. A series of three- and nine-story prototype SCSPSWs employing beam-only-connected web plates with design strengths comparable to that of the SC-SPSWs with fully-connected web plates presented in Clayton et al. [1] are presented, and the potential for column size and overall material reduction is assessed. Methods for modeling beam-only-connected web plates in SC-SPSWs are discussed and used to conduct nonlinear response history analyses of the prototype buildings to assess the impact of beam-onlyconnected web plates on SC-SPSW seismic response.

\section{Beam Demands}

Beams are a critical component in SC-SPSWs as they must resist complex distributions of axial forces, shear forces, and moment resulting from combined PT and web plate forces. Dowden et al. [2] presented a capacity design procedure for SC-SPSW beams with fully-connected web plates. Similar design methodologies can be used for SC-SPSW beams with beam-only-connected web plates; however, demands will differ due to the development of a PTF. Beamonly-connected web plates may be assumed to have a constant web plate stress acting only along the portion of the beam where the PTF occurs; for fullyconnected web plates, a constant stress is assumed to act along the entire length of the beam. In actuality, the web plate forces are not constant and vary slightly in magnitude and orientation; however, these variations are typically neglected in steel plate shear wall design.

Additionally, the angle of orientation of the PTF ( $\theta$ in Fig. 8) is different than that of the tension field orientation for a fully-connected web plate ( $\alpha$ in Fig. 1) . The PTF angle of inclination, $\theta$, can be calculated from the following equation:

$$
\tan (2 \theta)=\frac{L_{w}}{h_{c}}
$$

where, $L_{w}$ is the length of the web plate along the beam and $h_{c}$ is the clear height of the web plate $[13,14]$. Thus, the length of the PTF along the beam, 
$L_{P T F}$, can be determined as a function of web plate geometry:

$$
L_{P T F}=L_{w}-h_{c} \tan \theta
$$

From this equation, the portion of web plate over which the PTF is acting can be plotted as a function of web plate aspect ratio, $\frac{L_{w}}{h_{c}}$ (Fig. 4). Note that for beam-connected web plates, the web plate length, $L_{w}$, can be nearly equal to the beam length minus a small gap between the beam fish plate and the column flange to prevent binding under the expected PT connection rotation.

Notice that $\theta$, the angle of inclination of the PTF in a beam-only-connected web plate, depends only on web plate geometry, while $\alpha$, the angle of inclination of the tension field in a fully-connected web plate per current design recommendations [6], depends on web plate thickness, geometry, and boundary frame axial and flexural stiffness. Recent research suggests $\alpha$ approaches $45^{\circ}$ for fully-connected web plates after web plate yielding [15] and would be an appropriate value for use in design of fully-connected web plates.

The free-body diagram of an intermediate SC-SPSW beam with beamonly-connected web plates is shown in Fig. 5(a). The beam axial force and moment distributions can be determined by separating them into three different contributing components: the PT axial force acting at the rocking points (Fig. 5(b)), the vertical distributed web plate forces (Fig. 5(c)), and the horizontal distributed web plate forces (Fig. 5(d)). Below is a discussion of the beam demands attributed to each of these components.

\subsection{PT force at rocking points}

As the PT connection rocks open under lateral loading, the axial load in the beam is transferred through the rocking point (i.e. the extreme fiber of the opposite flanges on each end of the beam). A large potion of the beam axial load is due to the PT force, $T_{P T}$, which is a function primarily of the initial PT force, $T_{o}$; the beam depth, $d$; the gap opening angle, $\theta_{r}$; and the PT axial stiffness, $\left(\frac{E A}{L}\right)_{P T}$. The gap opening $\theta_{r}$ can be approximated as the column drift angle for relatively stiff boundary frame members. 
Although the compressive axial force in the beam due to the PT strands $\left(T_{P T}\right)$ is constant along its length, the moment developed by the axial force acting at the rocking points, $M_{P T}$, is linearly distributed (Fig. 6(a)) with equal and opposite moments of $T_{P T} \frac{d}{2}$ at each end. The constant shear due to the PT force, $V_{P T}$, is equal to $T_{P T} \frac{d}{L_{c f}}$, where $L_{c f}$ is the beam length.

\subsection{Vertical web plate forces}

Diagonal distributed loads acting on the beam result from the development of the PTF in the web plate. For capacity design of the beams, the web plate force can be taken as the expected yield strength, $R_{y} F_{y}$, of the web plate material acting at an angle $\theta$ from vertical, over a length $L_{P T F}$ along the beam. The vertical component of the web plate forces, $\omega_{y}$, can be found using the same method as those presented for fully-connected SPSW web plates by replacing $\alpha$ with $\theta[2,7]$. The following demand equations assume story drifts in adjacent stories are in the same direction, which produces an upper bound on beam demands appropriate for capacity design. These may overestimate demands if higher modes are important.

For beam-only-connected web plates, the web plate forces act over different portions above and below the beam, resulting in non-constant axial and shear distribution along the length of the web plate. The demand distributions attributed to the web plate forces can be calculated based on three distinct zones (described here for rightward lateral displacement as illustrated in Figs. 5 and 6).

Zone 1: Portion on the left end of the beam where web plate forces are only acting above the beam. $\left(0 \leq x \leq L_{c f}-L_{P T F(i)}\right.$ where $x=$ distance from the left end of the beam, $L=$ beam length, and $L_{P T F(i)}=$ length of PTF in story $i$ below the beam.)

Zone 2: Portion in the middle of the beam where web plate forces are acting above and below the beam. $\left(L_{c f}-L_{P T F(i)}<x \leq L_{P T F(i+1)}\right.$ where $L_{P T F(i+1)}=$ length of PTF in story $(i+1)$ above the beam.) 
Zone 3: Portion on the right end of the beam where the web plate forces are only acting below the beam. $\left(L_{P T F(i+1)}<x \leq L_{c f}\right)$

Because beam-only-connected web plates do not require corner cutouts to accommodate PT connection gap opening, the length of the web plate, $L_{w}$, can be taken as approximately equal to the length of the beam, $L_{c f}$, for purposes of design.

The moment distribution associated with the vertical component of the web plate forces, $M_{\omega_{y}}$ is (Fig. 6(b)):

$$
M_{\omega_{y}}(x)=\left\{\begin{array}{cc}
-V_{L, \omega_{y}} x+\frac{1}{2} \omega_{y(i+1)} x^{2} & \text { for Zone } 1 \\
\frac{-1}{2} \omega_{y(i)}\left(L_{c f}^{2}-2 L_{P T F(i)} L_{c f}+L_{P T F(i)}^{2}\right) \\
+\left(-V_{L, \omega_{y}}+\omega_{y(i)}\left(L_{c f}-L_{P T F(i)}\right)\right) x \\
+\frac{1}{2}\left(\omega_{y(i+1)}-\omega_{y(i)}\right) x^{2} & \text { for Zone } 2 \\
\frac{-1}{2} \omega_{y(i)}\left(L_{c f}-L_{P T F(i)}\right)^{2}-\frac{1}{2} \omega_{y(i+1)} L_{P T F(i+1)}^{2} \\
+\left(-V_{R, \omega_{y}}+\omega_{y(i)} L_{c f}\right) x-\frac{1}{2} \omega_{y(i)} x^{2} & \text { for Zone } 3
\end{array}\right.
$$

where, $V_{L, \omega_{y}}$ and $V_{R, \omega_{y}}$ can be determined from equilibrium of the partial freebody diagram shown in Fig. 5(c) as shown below.

$$
\begin{aligned}
V_{L, \omega_{y}} & =\omega_{y(i+1)}\left(L_{P T F(i+1)}-\frac{L_{P T F(i+1)}^{2}}{2 L_{c f}}\right)-\omega_{y(i)} \frac{L_{P T F(i)}^{2}}{2 L_{c f}} \\
V_{R, \omega_{y}} & =\omega_{y(i)}\left(L_{P T F(i)}-\frac{L_{P T F(i)}^{2}}{2 L_{c f}}\right)-\omega_{y(i+1)} \frac{L_{P T F(i+1)}^{2}}{2 L_{c f}}
\end{aligned}
$$

Although the moment distribution appears to be complex, the key take-away is that the vertical component of the PTF web plate load results in a parabolic moment distribution with concavity in the direction of the net vertical load (e.g. moment distribution is concave up where the net vertical web plate force is upwards). This results in double-curvature moment distribution as shown in Fig. 6(b). Fig. 6(b) shows example moment distributions where the web plate strength above and below the beam are equal $\left(\omega_{y(i)}=\omega_{y(i+1)}\right)$ and where the web plate below is stronger $\left(\omega_{y(i)}>\omega_{y(i+1)}\right)$. Note that if $\omega_{y(i)}=\omega_{y(i+1)}$ the 
sign of the moments due to the vertical web plate forces in Zones 1 and 3 are opposite in sign from those due to the PT forces. If $\omega_{y(i)}>\omega_{y(i+1)}$ the maximum moment appears in Zone 3, and its magnitude increases as the difference in web plate strength above and below, $\Delta w_{y}$, increases. For the extreme case of the top anchor beam where $\omega_{y(i+1)}=0$, there is no Zone 2 and the moment distribution equation for Zone 3 extends over a length $L_{c f}-L_{P T F(i)} \leq x \leq L$.

\subsection{Horizontal web plate forces}

The beam demands due to the horizontal web plate forces can be separated into the same three zones as described above. The partial free-body diagram shown in Fig. 5(d) assumes that the axial and shear beam end reactions due to the net horizontal web plate forces $\left(\frac{1}{2} P_{b(w)}\right.$ and $V_{\omega_{x}}$, respectively) are distributed equally to each end of the beam. This simplification is appropriate for design and SC-SPSW applications where inertial forces are transferred symmetrically to both boundary frame columns [16].

The net horizontal force acting on the beam due to the web plate forces, $P_{b(w)}$, (similar to $P_{H B E(V B E)}[6]$ for fully-connected web plates) is:

$$
P_{b(w)}=\omega_{x(i)} L_{P T F(i)}-\omega_{x(i+1)} L_{P T F(i+1)}
$$

The axial force distribution along the beam due to the horizontal web plate forces is:

$P_{\omega_{x}}(x)=\left\{\begin{array}{lc}-\frac{1}{2} P_{b(w)}-\omega_{x(i+1)} x & \text { for Zone } 1 \\ -\frac{1}{2} P_{b(w)}-\omega_{x(i)}\left(L_{c f}-L_{P T F(i)}\right)+\left(\omega_{x(i)}-\omega_{x(i+1)}\right) x & \text { for Zone } 2 \\ -\frac{1}{2} P_{b(w)}-\omega_{x(i+1)} L_{P T F(i+1)}-\omega_{x(i)}\left(L_{c f}-L_{P T F(i)}\right)+\omega_{x(i)} x & \text { for Zone } 3\end{array}\right.$

This equation shows the axial force distribution has a constant negative slope in Zone 1 (i.e. the axial demand is becoming more compressive approaching the middle of the beam) that is proportional to $\omega_{x(i)}$, a linear axial force distribution in Zone 2 that is proportional to the net horizontal web plate distributed force 
$\left(\Delta \omega_{y}=\omega_{x(i+1)}-\omega_{x(i)}\right.$, e.g. positive slope if $\left.\omega_{x(i+1)}>\omega_{x(i)}\right)$, and has a constant positive slope in Zone 3 (i.e. the axial demand is becoming less compressive approaching the right end of the beam); thus, the maximum compressive axial force is where Zones 1 and 2 meet.

The eccentricity of the horizontal forces acting on the beam produces shear forces along the beam. The shear end reaction force due to the horizontal web plate forces (shown in Fig. 5(d)) can be taken as:

$$
V_{\omega_{x b}}=\frac{d}{2 L_{c f}}\left(\omega_{x(i)} L_{P T F(i)}+\omega_{x(i+1)} L_{P T F(i+1)}\right)
$$

The piecewise-linear moment distribution due to the horizontal web plate forces, $M_{\omega_{x}}$, is:

$M_{\omega_{x}}(x)=\left\{\begin{array}{cc}\frac{d}{4} P_{b(w)}+\left(-V_{\omega_{x}}+\frac{d}{2} \omega_{x(i+1)}\right) x & \text { for Zone } 1 \\ \frac{d}{4} P_{b(w)}-\frac{d}{2} \omega_{x(i)}\left(L_{c f}-L_{P T F(i)}\right)+\left(-V_{\omega_{x}}+\frac{d}{2}\left(\omega_{x(i+1)}+\omega_{x(i)}\right)\right) x \\ \begin{array}{cc}\frac{d}{4} P_{b(w)}+\frac{d}{2}\left(\omega_{x(i+1)} L_{P T F(i+1)}-\omega_{x(i)}\left(L_{c f}-L_{P T F(i)}\right)\right) \\ +\left(-V_{\omega_{x}}+\frac{d}{2} \omega_{x(i)}\right) x & \text { for Zone } 2\end{array}\end{array}\right.$

A sample distribution of $M_{\omega_{x}}$ is shown in Fig. 6(c) for cases where $\omega_{x(i)}=$ $\omega_{x(i+1)}$ and where $\omega_{x(i)}>\omega_{x(i+1)}$. Note that the moment variation along the beam due to the horizontal web plate forces is relatively small in magnitude and is centered about the moment corresponding to the axial beam end reactions acting at the rocking point, $\frac{d}{4} P_{b(w)}\left(\right.$ centered about 0 when $\left.\omega_{x(i)}=\omega_{x(i+1)}\right)$.

\subsection{Combined beam demands}

The axial and moment demands from the three contributions described above can be combined using superposition to determine the total axial force and moment distributions along the beam, a schematic of which is shown in Fig. 7 for cases when $\omega_{(i)}=\omega_{(i+1)}$ and where $\omega_{(i)}>\omega_{(i+1)}$.

Fig. 7(a) shows that the maximum compressive axial force is largest where Zones 1 and 2 meet. Fig. 7(b) shows the complex double-curvature moment 
distribution along the beam. For cases where $\Delta \omega$ is small, the maximum moment occurs at the beam ends. Where $\omega_{(i)}$ is significantly larger than $\omega_{(i+1)}$, it is possible for the maximum moment to occur in Zone 3 near the middle of the beam.

As described in Dowden et al. [2], it is undesirable for hinging to occur within the beam span for fully-connected web plate SC-SPSWs (and SPSWs); therefore, the beam capacity design procedure recommended by Dowden et al. [2] requires $T_{P T}$ to be sufficiently large at target drift levels to ensure the maximum moment occurs at the beam end to prevent formation of in-span plastic hinges. For fully-connected web plates, the formation of in-span plastic hinges and associated accumulation of plastic deformation in the beam under cyclic loading adversely impacts formation of the web plate tension field, resulting in a significant decrease in web plate lateral load carrying capacity [17]. For beamonly-connected web plates, formation of a plastic hinge near the middle of the beam may not have such negative impacts as the PTF is already assumed to inherently act only over a portion of the beam (between $55 \%$ and $70 \%$ of the beam length for typical web plate aspect ratios as shown in Fig. 4). Further research is necessary to assess the impact of in-span beam hinging on PTF development in beam-only-connected web plates.

\subsection{Verification of beam demands using pushover analysis}

To verify the beam demand equations presented above, a numerical pushover analysis of a one-story SC-SPSW model with beam-only-connected web plates was conducted in OpenSees [18], and the numerical beam demands were compared to those derived analytically. To simulate the PTF of the beam-onlyconnected web plate, a modified strip model was used. The strip model is a widely-employed method for simulating tension field behavior in SPSW web plates [6] and has been used for previous SC-SPSW numerical studies with fullyconnected web plates $[1,4]$. Previous SPSW [11] and SC-SPSW [4] studies have successfully employed the strip method to simulate the PTF of the beam-onlyconnected web plate. Here, the strips are located in the PTF and are oriented 
at an angle $\theta$ (Eqn. (1)).

A schematic of the one-story SC-SPSW model is shown in Fig. 8, where the partial tension field strips are provided for each direction of loading. The web plate was assumed to be $0.8 \mathrm{~mm}$ thick, and the web plate yield strength was taken as the expected yield strength, $F_{y}$, of A36 steel (248 MPa) with near-zero strain hardening. The web plate was modeled using a tension-only (TO) strip material as suggested in the AISC Design Guide 20: Steel Plate Shear Walls [6] for design of SPSWs with fully-connected web plates.

The total PT cross-sectional area was taken as 790 sq. mm, and the total initial PT force was $865 \mathrm{kN}$. The PT boundary frame was modeled as described in Clayton et al. [1] using beam-column elements for the beams and columns, truss elements with an initial stress for the PT elements, compressions-only springs at the end of the beam flanges to simulate rocking PT connection behavior, and diagonal springs to simulate shear transfer in the PT connection (Fig. 8). For purposes of comparison with the beam demand expressions, the beams and columns were assumed to be elastic and essentially rigid. The single-story SCSPSW was pushed with equal forces applied at the top of each column as shown in Fig. 8 up to $2 \%$ drift.

The axial force and moment demands along the beam were calculated using equations presented previously, and plotted with those taken from the numerical model (Model TO in Fig. 9). Note that the beam in this one-story example represents the case where $\omega_{(i+1)}=0$, resulting in only two zones of loading along the beam as described previously. Fig. 9 shows that the beam demand equations provide a reasonable approximation of beam demands from a partial tension field strip model in a pushover analysis. Thus the equations are deemed appropriate for use in design of the beams.

\section{Beam-only-connected SC-SPSW Designs}

To compare approximate material cost and seismic performance of SC-SPSWs with beam-only-connected and fully-connected web plates, a series of three- and 
nine-story SC-SPSWs with beam-only-connected web plates were designed to have the same lateral design strength as the prototype SC-SPSWs with fullyconnected web plates presented in Clayton et al. [1]. For purposes of comparison, the distribution of lateral load capacity between the PT frame and the web plates were kept relatively equal for beam-only-connected and fully-connected web plate designs. This ensured that differences in seismic performance could not be attributed to differences in relative strengths of the web plates and PT frame. To meet this requirement, the same initial PT force and nominal beam and column depths were used for both web plate types to ensure similar PT frame strengths, and the web plate thicknesses $\left(t_{w}\right)$ of the beam-only-connected web plates were increased such that the web plate design shear strengths equal those of the fully-connected web plates.

The nominal lateral strength for beam-only-connected web plates, $V_{n}$, can be taken from the equation of nominal strength of fully-connected web plates presented in the AISC Seismic Provisions [19] by replacing the tension field angle of inclination, $\alpha$, with that of a beam-only-connected partial tension field, $\theta$, and by replacing the total fully-connected web plate length, $L_{w}$, with the partial tension field length, $L_{P T F}$ :

$$
V_{n}=0.42 F_{y} t_{w} L_{P T F} \sin (2 \theta)
$$

where the 0.42 factor comes from the theoretical lateral strength $\left(0.50 F_{y} t_{w} L_{P T F} \sin (2 \theta)\right)$, which is simply the sum of the horizontal forces from the partial tension field, divided by an overstrength factor of 1.2 to be consistent with other seismic force-resisting systems [6].

Assuming web plates of both types (beam-only-connected and fully-connected) have the same yield strength, $F_{y}$, the thickness of a beam-only-connected web plate must be increased by a factor of $\beta_{w e b}$ to provide the same strength as a fully-connected web plate.

$$
\beta_{w e b}=\frac{t_{w, \text { beam-only }}}{t_{w, \text { fully-conn. }}}=\frac{L_{w} \sin (2 \alpha)}{L_{P T F} \sin (2 \theta)}
$$

where $L_{w}$ here is the length of the fully-connected web plate connected to the 
beam (which may be less than $L_{w}$ of the beam-only-connected web plate due to the corner cutouts). For the following approximations: $\alpha=43^{\circ}$ and $L_{w}$ for both fully-connected and beam-only-connected web plates are equal (this assumption ignores the corner cutouts in fully-connected web plates), the ratio of beam-only-connected to fully-connected web plate required thicknesses can be estimated as a function of web plate aspect ratio, $L_{w} / h_{c}$, as shown in Fig. 10. Values of $\beta_{w e b}$ will further decrease if the corner cutout is accounted for in fully-connected web plates.

The AISC Seismic Provisions [19] limit SPSWs to aspect ratios $\left(L_{w} / h_{c}\right)$ of 0.8 to 2.5 . For common aspect ratios between 1 and 2 , the thickness of beamonly-connected web plates would need to be approximately 1.5 to 2.5 times thicker than fully-connected web plates to provide the same lateral strength. The required increase in $t_{w}$ for beam-only-connected web plates decreases as the aspect ratio increases, suggesting that beam-only-connected web plates may be used more efficiently in wider bays (i.e. larger $L_{w}$ ) as less web plate material is required to provide the same lateral strength as fully-connected web plates of the same strength. Because web plate thicknesses are typically small, using thicker web plates may actually provide advantages for welding and handling.

The prototype buildings considered in this study were based on the threeand nine-story SAC buildings [20] located in the Los Angeles, CA area. Clayton et al. [1] developed designs for SC-SPSWs with fully-connected web plates with bay widths of $4.6 \mathrm{~m}$ for the three- and nine-story buildings. Designs were developed using the spectral response parameters for the seismic hazard levels of $50 \%, 10 \%$, and $2 \%$ probability of exceedence seismic hazard levels (referred to as 50/50, 10/50, and 2/50, respectively) as defined by FEMA [20] for the Los Angeles location [1]. Various prototype SC-SPSWs were designed for each building height. These variations included the number of walls in each direction of the building (i.e. the portion of the total seismic shear resisted by each wall) and whether or not the optional performance objective of elastic behavior at the 50/50 hazard level was considered in the design.

Designs of the SC-SPSWs with fully-connected web plates followed the performance- 
based seismic design methodology developed by Clayton et al. [1]. This method includes an optional performance objective of elastic response at the 50/50 hazard level. Those designs that considered the optional performance objective were designed using the elastic story shears determined from the 50/50 spectral accelerations $\left(V_{50 / 50}\right)$, which were larger than code-based design forces for this location. Designs that did not consider this optional performance objective were designed using code-based design level forces reduced by a response modification factor, $R\left(V_{D B E} / R\right)$. For this location, the $10 / 50$ hazard level is a reasonable approximation of the design-basis earthquake (DBE); therefore, the $10 / 50$ spectral accelerations were used to calculate $V_{D B E}$.

Note that the SC-SPSW design procedure presented in Clayton et al. [1] utilized a lateral load distribution based on inelastic structural response developed by Chao et al. [21] to account for higher mode effects. This lateral load distribution was used instead of the traditional equivalent lateral force distribution used in ASCE 7 [22]. The ASCE 7 distribution was found to result in designs that had significantly larger upper story drifts relative to those designed using the distribution by Chao et al., similar to the observations made in self-centering moment-resisting frame systems designed using the equivalent lateral force distribution [23]. Using the inelastic force distribution [21] resulted in more uniform story drift distributions in SC-SPSWs with fully-connected and beam-only-connected web plates.

In the performance-based design approach for SC-SPSWs with fully-connected web plates[1], the beams and columns are capacity designed as the web plates are the intended ductile yielding element. Unlike conventional SPSWs, where flexural-axial hinges are expected to form at the ends of the beams, beams in SC-SPSWs are expected to remain elastic. Thus the moment that develops at the end of the beams is a function of the web plate forces and the PT elongation, which is a function of the connection gap rotation that can be conservatively approximated as the story drift demand. Thus, capacity design of the boundary frame is not based on the plastic moment capacity of the beams, but rather the demands associated with the expected target drift, at which the beams and 
columns are expected to be elastic. The target drift demands of $4 \%$ and $5 \%$ were used for capacity design of the beams and columns, respectively. These values were selected based on median 2/50 peak story drift demands of $4 \%$ observed in preliminary studies of SC-SPSWs with fully-connected web plates modeled using idealized tension-only web plate response. For consistency between the two SC-SPSW web plate designs, the beams and columns in the beam-onlyconnected SC-SPSWs were capacity designed assuming the same target drift demands of $4 \%$ and $5 \%$ for the beams and columns, respectively. The appropriateness of this assumption will be evaluated based on results of the response history analyses.

Table 1 provides representative design parameters for the beam-only-connected SC-SPSW designs. The naming scheme for the SC-SPSW designs is as follows: (number of stories)-(web plate design force, where ' $50 / 50$ ' represents $V_{50 / 50}$ and '10/50' represents $V_{D B E} / R$ )-(number of walls in each direction of the building). The ' $\mathrm{B}$ ' following the name signifies that the design is for a SC-SPSW with beam-only-connected web plates. For the 9-story SC-SPSWs, details are provided for the 1st, 2nd, 5th, 8th, and 9th stories to show the range of design parameters throughout the building; details for the remaining stories can be found in Clayton [16]. The web plate thicknesses given in Table 1 do not represent actual available plate thicknesses as the given thicknesses were calculated to provide the same lateral strength as the fully-connected web plate designs. The beams and columns were selected from standard U.S. W-shapes. Further details of the fully-connected web plate SC-SPSW designs can be found in Clayton et al. [1]. Note that the Clayton et al. [1] study found the nine-story fully-connected web plate SC-SPSWs designed to remain elastic in the 50/50 hazard level (i.e. 9-5050-10) produced overly conservative and significantly overperforming designs; therefore, this prototype SC-SPSW is not considered in this study.

Table 2 shows the percentage of steel weight savings for the beam-onlyconnected SC-SPSW designs compared to the fully-connected web plate designs. Here, a positive value represents a reduction in material and a negative 
value represents an increase in steel material for beam-only-connected web plate designs relative to the similar fully-connected web plate designs. Note that although the weight of web plate material increases, the decrease in beam and column sizes typically resulted in a significant decrease in overall steel weight. Also note that each of the beam-only-connected SC-SPSWs designs use the same bay width $(4.6 \mathrm{~m})$ as the fully-connected SC-SPSWs considered in Clayton et al. [1]; therefore, these conclusions of weight savings are only valid for this particular panel aspect ratio. Further research is required to assess the potential weight savings for a broad range of aspect ratios.

The PT and boundary frame members were designed using the same procedures and methodologies for both the fully-connected and beam-only-connected web plate SC-SPSWs. The only exception to this was that the design requirement for ensuring the maximum moment occur at the end of the beam at the target drift was relaxed for the beam-only-connected web plate designs as the effects of in-span hinging are not thought to be as severe. This design requirement typically controlled design of the PT elements in the top beams of the fully-connected web plate SC-SPSWs where the unbalanced vertical web plate forces are largest. For the beam-only-connected web plate designs, the PT designs in the top beams were taken as equal to the fully-connected web plate designs such that the PT frame strengths at this location were equal for both web plate design types.

\section{Nonlinear Models for Seismic Evaluation}

Web plate strips are typically modeled and designed using a tension-only (TO) pinched hysteretic response as suggested by Sabelli and Bruneau [6]; however, experimental testing of SC-SPSWs [4] showed that the web plate lateral resistance during unloading was not negligible as is assumed in the tension-only strip method. Clayton et al. [4] showed that a modified tension-compression (TC) strip material model with a compressive strength equal to $25 \%$ of the web plate yield strength provides improved, in comparison with a tension-only 
strip model, simulation of experimental response (as shown in Fig. 11). Fig. 11 shows that the TC model underestimates the energy dissipation and stiffness during reloading and accurately predicts the resistance during unloading in the fully-connected web plate specimen (Fig. 8), while it underestimates the energy dissipation and web plate resistance during unloading and accurately predicts the reloading response in the beam-only-connected web plate specimen (Fig. 8). Further discussion of results can be found in Clayton et al. [4].

Strain gages along the middle beam of the beam-only-connected SC-SPSW experimental specimen shown in Fig. 8 were also used to determine moment demands at discrete points along the length of the beam [4]. Fig. 12 shows the experimentally-determined moments, along with the moment distribution determined from the equations presented in Section 2 and the moment demands from numerical models of the specimen. The moment demands are shown for two numerical models - one employing the tension-only (TO) strip material, and the other employing the tension-compression (TC) strip material described above. Fig. 12 shows that the experimentally-determined moment demands match well with those predicted by the equations presented in Section 2 and those from numerical models. Note that for this beam with web plates above and below, the beam moment demands are not sensitive to the amount of compression included in the strip material model as demands from both numerical models are essentially the same.

While the TC model does have some shortcomings in predicting the complex web plate behavior, these shortcomings could be expected to produce conservative, overestimations of peak drift demands and residual drifts when used is nonlinear response history analyses. Therefore, the TC model is used in this numerical study. Additional discussion of the TC strip model, including comparisons with experiments and more complex shell element web plate models can be found in Clayton [16]. Further research is warranted to fully understand the complex hysteretic behavior of beam-only-connected web plates and further validate the use of the tension-compression partial tension field strip model for a wide range of geometries and load conditions. 
Fig. 13 shows an idealization of the OpenSees [18] model used to simulate response of the SC-SPSW from the prototype buildings with fully-connected and beam-only-connected web plates. The TC strip model was employed to simulate web plate response, and the PT connection was modeled as previously shown in Fig. 8. The columns were assumed to be pinned at their bases (as was done for the SC-SPSWs with fully-connected web plates in Clayton et al. [1]). The boundary frame was modeled using nonlinear beam-column elements with fiber cross-sections that allow for distributed yielding to occur anywhere along the length of the beams or columns such that the effects of in-span hinging, although unlikely to occur, were simulated. The PT and boundary frame yield strengths were taken as 1,689 $\mathrm{MPa}$ and $345 \mathrm{MPa}$, respectively. The web plate yield strength was taken as the expected yield strength, $R_{y} F_{y}$, of A36 steel (322 MPa) with $0.2 \%$ strain hardening up to a strain of 10 times the yield strain, followed by $1 \%$ isotropic strain hardening. The compressive strength of the TC strip was taken as $25 \%$ of the web plate yield strength, and the tensile yield strength of the TC strip was reduced by the same amount such that the combined tensile and compressive resistance of the strips in both tension field directions equal the expected yield strength. Further information on the TC strip material is given in Clayton et al. [4].

The seismic mass was simulated as lumped masses in the columns at the the location of the PT connections. P-Delta effects were simulated with gravity loads applied to two P-Delta columns placed symmetrically on both sides of the wall. Rayleigh damping of $2 \%$ was considered in the first and third modes for the three-story buildings and the first and fourth modes in the nine-story buildings $[1]$.

The three-story and nine-story SC-SPSWs were subjected to ground motions developed for the Los Angeles location as part of the SAC project [20]. The ground motion ensemble includes twenty motions at each of the following seismic hazard levels: 50/50, 10/50, and 2/50. No further scaling was done to the ground motions. The three-story models were subjected to the full suite of sixty ground motions, while the nine-story models were subjected to only ten ground 
motions at each hazard level (thirty total). A partial set of ground motions was used for the nine-story models to reduce overall computational runtimes. The ground motions selected for this partial set are given in Table 3 and were selected from those with relatively shorter durations that produced near-median peak drift demands based on previous SC-SPSW numerical studies.

Note that the results from the fully-connected SC-SPSW models presented below differ from those presented in Clayton et al. [1]. The results presented in Clayton et al. [1] were done using the tension-only strip material model. Experimental and numerical investigations conducted after the publication of this initial proof-of-concept study emphasized the importance of non-negligible web plate-residual strength on SC-SPSW seismic performance. The numerical results for the fully-connected web plate SC-SPSWs presented here use the same models and web plate material specifications as those in the Clayton et al. [1] study; however, the original tension-only behavior is replaced with the modified tension-compression behavior.

The compressive strength in the TC model employed in each of these SCSPSWs was taken as $25 \%$ of the web plate yield strength. Webster [24] shows that for thicker web plates, such as those used in some of the three-story beamonly-connected designs, the compressive unloading resistance may be larger than this amount. For purposes of comparison, the web plate compressive resistance was kept constant at $25 \%$ of yield for all of the models, representing a conservative lower bound for web plate unloading strength. Consideration of the additional compressive resistance of the thicker web plates could be expected to improve seismic performance by increasing energy dissipation and reducing peak drift demands. Further details of the seismic response of SC-SPSWs considering larger web plate unloading resistances for thicker web plates are provided in Clayton [16]. 


\section{Results of Nonlinear Response History Analyses}

The key response parameters that were evaluated during dynamic analyses were peak story drifts $\left(\theta_{s}\right)$, maximum residual story drifts $\left(\theta_{\text {resid }}\right)$, and beam and column demand-to-capacity values $\left(D_{b}\right.$ and $D_{c}$, respectively) taken as the interaction value from Eqn. H1-1 in the AISC Specification [25]. The beam and column demand-to-capacity values are calculated assuming sufficient lateral support for the boundary frame members to reach the full plastic moment. The beams are short and in double curvature so lateral torsional buckling is not simulated in the numerical models. Further, lateral bracing would be provided if necessary. The values for $D_{b}$ and $D_{c}$ are taken as the maximum interaction equation values evaluated throughout the entire time history and along the entire length of the beam and column elements, respectively. The locations at which the maximum $D_{b}$ and $D_{c}$ occur vary with respect to SC-SPSW design due to overstrength using available $\mathrm{W}$-shapes and vary with respect to ground motion depending on the location of peak story drift demands.

Median values $\left(\mu_{1 / 2}\right)$ for each of these response parameters at each of the seismic hazard levels are given in Table 4. The prototype SC-SPSW name is listed in the first column. The results from the fully-connected TC web plate models are indicated with a ' $\mathrm{FC}$ ' in the column header, and results from the beam-only-connected TC web plate models are indicated with a 'BO' in the column header. For easier comparison, the ratio of the median beam-onlyconnected response to the median fully-connected response ('BO/FC').

A general comparison and evaluation of median response parameters is made for each of the fully-connected and beam-only-connected web plate SC-SPSW designs. Recentering is evaluated based on residual story drifts less than $0.2 \%$, corresponding to out-of-plumb construction limits [1]. Boundary frame yielding is evaluated based on the $D_{b}$ and $D_{c}$ values, with values greater than one indicating significant inelastic response due to combined axial and flexural demands.

The peak story drift demands for the beam-only-connected web plate SC- 
SPSWs were larger than those for the fully-connected models at all hazard levels, typically 10-60\% larger (with the exception of the 3-5050-6 design, where the peak drifts of the fully-connected SC-SPSW were significantly smaller, resulting in larger a larger $\mathrm{BO} / \mathrm{FC}$ ratio). The larger story drifts are due in part to the decrease in column flexural stiffness in the beam-only-connected designs. Additionally, the fully-connected web plates have some portion of the plate (or strips) that are connected to both the beam and column; this provides some restraint to $\mathrm{PT}$ connection gap rotation at that location and reduces peak drift demands. Although the beam-only-connected SC-SPSWs experience larger drift demands, the median peak drift demands at the 10/50 hazard level (an approximation for a DBE) are typically well below the code-specified $2 \%$ design drift limit (with the exception of 3-1050-4B model which was slightly larger).

The maximum residual story drifts for all models are relatively small, even with the conservative overestimation of the web plate unloading strength during free-vibration (when actual web plate unloading resistance decreases [5]). Neither web plate connectivity type appears to consistently have larger residual drifts as residual drifts are largely a function of the occurrence of significant PT frame yielding. All of the models were able to recenter $\left(\theta_{\text {resid,max }}<0.2 \%\right)$ at the median level in the 10/50 hazard level as targeted in the performance objectives presented in Clayton et al. [1]. Furthermore, although several of the SC-SPSWs recentered after the 2/50 hazard level ground motions, those that did not meet the recentering criterion still had relatively small residual drifts.

In general, the boundary frame interaction values were just at or less than one at the 2/50 hazard level, indicating only minor yielding at this hazard level and thus meeting the proposed collapse prevention performance objective [1]. This is consistent with results for the peak drift. The occurrence of beam and column yielding is largely a function of the peak drift as boundary frame design forces are calculated directly from targeted drift demands $[2,1]$. According to the design procedure outlined in Clayton et al. [1], the beams are capacity designed for demands corresponding to the expected 2/50 drift demand of $4 \%$, while the columns are capacity designed for $5 \%$ drift to prevent soft-story 
collapse; however, yielding may occur in the boundary frame prior to these target drift levels due to dynamic effects not considered in the capacity design procedures $[2,7]$.

The portion of story shear resisted by the PT boundary frame was also similar for both fully-connected and beam-only-connected web plate designs, ranging from $20-40 \%$ of the peak story shear at the 10/50 hazard level and up to $50 \%$ of the story shear at the $2 / 50$ hazard level. This result indicates that the change in column sizes does not significantly impact the relative lateral resistance provided by the PT frame and the web plate as the PT frame strength is largely governed by PT connection stiffness (i.e. amount of PT and beam depth) and connection rotation demands.

The effects of consideration of the optional 50/50 performance objective and variation in the number of SC-SPSW bays in the buildings on seismic performance are similar for fully-connected and beam-only-connected SC-SPSWs. Consideration of the optional 50/50 performance objective (e.g. comparing the 3-5050-6 responses to the 3-1050-6 responses) resulted in larger, more conservative designs. As a result the 3-5050-6 designs had significantly lower peak drift demands and boundary frame interaction values compared to the 3-1050-6 designs. Increasing the number of SC-SPSW bays in the building (e.g. comparing the 3-1050-4 responses to the 3-1050-6 responses and comparing the the 9-1050-6, -8, and -10 responses) did not appear to have a significant effect on the seismic performance. Similar trends were observed in the response of tensiononly fully-connected web plate SC-SPSWs in Clayton et al. [1].

\section{Conclusions}

The SC-SPSW is a lateral force-resisting system capable of providing enhanced seismic performance, including recentering and mitigation of costly boundary frame damage. While research on this new lateral system is growing, initial experimental and analytical research indicated potential improvements that may further enhance SC-SPSW performance and economy. Those potential improve- 
ments include reduction of column sizes and mitigation of web plate damage to further improve ductility. (Note that using current design and construction techniques, the ductility of SC-SPSWs is comparable to that of SPSWs $[4,26]$; however, SPSWs can rely on the redundancy of the moment-resisting boundary frame to dissipate energy in the event of significant web plate tearing, whereas SC-SPSWs must rely only on the web plate for energy dissipation. Improvements made to delay and mitigate web plate tearing in SC-SPSWs will further enhance performance under extreme seismic events.)

Connecting the web plate to the beams only has been proposed as a means of reducing column size and mitigating web plate damage. Releasing the web plate from the columns eliminates the distributed load on the columns, significantly simplifying design as the maximum moments are ensured to be located at a beam-to-column or base connection (as opposed to the parabolic column moment distribution for fully-connected web plates which have the potential for column hinging anywhere along the height of the column). Additionally, releasing the web plates from the columns reduces the net horizontal strain in the web plate caused by frame expansion and reduces the localized out-of-plane deformations at the vulnerable ends of the web plate-to-boundary frame connection where web plate tearing is typically initiated.

To have comparable lateral strength, the beam-only-connected SC-SPSW must use stronger or thicker web plates than an equivalent fully-connected SCSPSW due to the decrease in the extent of the tension field. Although the required web plate thickness is larger for beam-only-connected SC-SPSWs, the reduction in beam and column demands can result in a significant savings of steel compared with fully-connected SC-SPSWs, particularly for taller buildings (as shown in Table 2). Additional potential cost savings beyond reduction of steel weight include being able to use more commonly available column Wsections and reducing labor for web plate installation. Expressions for beam axial force and moment design demands were developed for SC-SPSWs with beam-only-connected web plates. These expressions can be used directly for capacity design of the beams in the existing performance-based seismic design 
procedure presented in Clayton et al. [1]. For this study, the design requirement to prevent in-span hinging in the beams at the target drift was relaxed; however, further research is required to fully understand the impact of in-span hinging on beam-only-connected web plates.

Nonlinear dynamic behavior of the beam-only-connected SC-SPSWs was simulated using a PTF strip model with a strip material that conservatively simulates the effects of non-negligible web plate unloading strength. While this partial tension field strip model has been used to adequately predict cyclic response of beam-only-connected web plates (in both SPSW and SC-SPSW applications), the scope of research on the topic is limited. For this study, this PTF tension-compression strip model was used to conservatively approximate web plate behavior as it was expected to produce larger peak drifts and residual deformations under dynamic loading than a more refined model.

Numerical models of three- and nine-story SC-SPSWs employing both beamonly-connected and fully-connected web plates and designed to have equal lateral strengths were subjected to a series of ground motions representing the 50/50, 10/50, and 2/50 seismic hazard levels. Results showed that while the beam-only-connected SC-SPSWs had larger peak drift demands than their fullyconnected web plate counterparts, SC-SPSWs with beam-only-connected web plates were still able to meet the performance-objectives proposed in Clayton et al. [1], including recentering with no frame yielding in the 10/50 hazard level and collapse prevention with minor frame yielding in the 2/50 hazard level. These results suggest that the proposed performance-based design methodology can meet intended performance objectives and that beam-only-connected web plates can be used as a viable method for reducing overall steel weight in SCSPSWs without detrimentally impacting seismic performance. This study only considered one particular web plate aspect ratio; therefore, further research is necessary to see if similar steel weight reductions and seismic performance are expected for a wide range of SC-SPSW geometries. 


\section{Acknowledgments}

Financial support for this study was provided by the National Science Foundation as part of the George E. Brown Network for Earthquake Engineering Simulation under award number CMMI-0830294. P. Clayton was also supported by the National Science Foundation Graduate Research Fellowship under Grant No. DGE-0718124. Many of the numerical analyses presented in this paper were done using resources provided by the Holland Computing Center of the University of Nebraska and by the Open Science Grid (OSG), which is supported by the National Science Foundation and the U.S. Department of Energy's Office of Science. Any opinions, findings, conclusions, and recommendations presented in this paper are those of the authors and do not necessarily reflect the views of the sponsors.

\section{References}

[1] P. M. Clayton, J. W. Berman, L. N. Lowes, Seismic Design and Performance of Self-Centering Steel Plate Shear Walls, Journal of Structural Engineering 138 (2012) 22-30.

[2] D. M. Dowden, R. Purba, M. Bruneau, Behavior of Self-Centering Steel Plate Shear Walls and Design Considerations, Journal of Structural Engineering (138) (2012) 11-21.

[3] P. M. Clayton, T. B. Winkely, J. W. Berman, L. N. Lowes, Experimental Investigation of Self-Centering Steel Plate Shear Walls, Journal of Structural Engineering 138 (2012) 952-960.

[4] P. M. Clayton, J. W. Berman, L. N. Lowes, Subassembly testing and modeling of self-centering steel plate shear walls, Engineering Structures 56 (2013) 1848-1857.

[5] D. M. Dowden, P. M. Clayton, C.-H. Li, J. W. Berman, M. Bruneau, K.-C. Tsai, Full-scale Pseudo-dynamic Testing of Self-Centering Steel Plate Shear Walls, Journal of Structural Engineering (submitted). 
[6] R. Sabelli, M. Bruneau, Design Guide 20: Steel Plate Shear Walls, American Institute of Steel Construction, Chicago, IL, 2007.

[7] J. W. Berman, M. Bruneau, Capacity Design of Vertical Boundary Elements in Steel Plate Shear Walls, Engineering Journal 45 (1) (2008) 57-71.

[8] D. Borello, L. Fahnestock, Seismic Design and Analysis of Steel Plate Shear Walls with Coupling, Journal of Structural Engineering 139 (2013) 12631273 .

[9] R. Purba, M. Bruneau, Finite-Element Investigation and Design Recommendations for Perforated Steel Plate Shear Walls, Journal of Structural Engineering 135 (11) (2009) 1367-1376.

[10] L. Guo, Q. Rong, X. Ma, S. Zhang, Behavior of Steel Plate Shear Wall Connected to Frame Beams Only, International Journal of Steel Structures 11 (4) (2011) 467-479.

[11] C. Vatansever, N. Yardimci, Experimental Investigation of Thin Steel Plate Shear Walls with Different Infill-to-Boundary frame Connections, Steel and Composite Structures 11 (3) (2011) 251-271.

[12] I.-R. Choi, H.-G. Park, Steel Plate Shear Walls with Various Infill Plate Designs, Journal of Structural Engineering 135 (7) (2009) 785-79.

[13] L. J. Thorburn, G. L. Kulak, C. J. Montgomery, Analysis of steel plate shear walls, Structual Engineering Report 107, Dept. of Civil Engineering, University of Alberta, Edmonton, Alberta, Canada, 1983.

[14] K. Basler, Strength of plate girders in shear, Fritz Laboratory Report 25120, Lehigh University, Fritz Laboratory, Bethlehem, Pennsylvania, 1961.

[15] D. J. Webster, J. W. Berman, L. N. Lowes, Experimental Investigation of SPSW Web Plate Stress Field Development and Vertical Boundary Element Demand, Journal of Structural Engineering 140 (6) (2014) 04014011. 
[16] P. M. Clayton, Self-Centering Steel Plate Shear Walls: Subassembly and Full-scale Testing, Ph.D. dissertation, Civil and Environmental Engineering Dept., University of Washington, Seattle, WA, 2013.

[17] R. Purba, M. Bruneau, Impact of Horizontal Boundary Elements Design on Seismic Behavior of Steel Plate Shear Walls, Technical Report MCEER10-0007, Multidisciplinary Center for Earthquake Engineering Research, Buffalo, New York, 2010.

[18] S. Mazzoni, F. McKenna, M. Scott, G. Fenves, Open System for Earthquake Engineering Simulation User Command-Language Manual - OpenSees Version 2.0, Pacific Earthquake Engineering Research Center, University of California, Berkeley, Berkeley, CA, 2009.

[19] AISC, Seismic Provisions for Structural Steel Buildings, ANSI/AISC 34105, American Institute of Steel Construction, Chicago, IL, 2005.

[20] FEMA, State of the Art Report on Systems Performance of Steel Moment Frames Subject to Earthquake Ground Shaking, Tech. Rep. 355c, Helmut Krawinkler, Team Leader, SAC Joint Venture for the Federal Emergency Management Agency, Washington, D.C., 2000.

[21] S.-H. Chao, S. C. Goel, S.-S. Lee, A Seismic Design Lateral Force Distribution Based on Inelastic State of Structures, Earthquake Spectra 23 (3) (2007) 547-569.

[22] ASCE, Minimum Design Loads for Buildings and Other Structures, ASCE/SEI 7-10, Reston, VA, 2010.

[23] M. Garlock, Design, Analysis, and Experimental Behavior of Seismic Resistant Post-tensioned Steel Moment Resisting Frames, Ph.D. dissertation, Civil and Environmental Engineering Dept., Lehigh University, Bethlehem, PA, 2002.

[24] D. Webster, The Behavior of Un-stiffened Steel Plate Shear Wall Web Plates and Their Impact on the Vertical Boundary Elements, Ph.D. dis- 
sertation, Civil and Environmental Engineering Dept., University of Washington, Seattle, WA, 2013.

[25] AISC, Specification for Structural Steel Buildings, ANSI/AISC 360-05, American Institute of Steel Construction, Chicago, IL, 2005.

[26] J. W. Berman, M. Bruneau, Experimental Investigation of Light-Gauge Steel Plate Shear Walls, Journal of Structural Engineering 131 (2) (2005) $259-267$. 
Table 1: Design parameters for prototype SC-SPSWs with beam-only-connected web plate designs

\begin{tabular}{|c|c|c|c|c|c|c|}
\hline Name & Story & $\begin{array}{l}t_{w} \\
(\mathrm{~mm})\end{array}$ & $\begin{array}{c}T_{o} \\
(\mathrm{kN})\end{array}$ & $\begin{array}{c}\text { \# PT } \\
\text { strands }\end{array}$ & $\begin{array}{l}\mathrm{HBE} \\
\text { size }\end{array}$ & $\begin{array}{l}\text { VBE } \\
\text { size }\end{array}$ \\
\hline \multirow[t]{3}{*}{$3-5050-6 \mathrm{~B}$} & 1 & 17.76 & 231 & 16 & $\mathrm{~W} 24 \times 250$ & $\mathrm{~W} 14 \mathrm{x} 455$ \\
\hline & 2 & 13.20 & 503 & 12 & W30x211 & $\mathrm{W} 14 \times 455$ \\
\hline & 3 & 8.44 & 467 & 32 & W36x302 & $\mathrm{W} 14 \mathrm{x} 455$ \\
\hline \multirow[t]{3}{*}{$3-1050-4 B$} & 1 & 7.02 & 356 & 24 & $\mathrm{~W} 24 \times 146$ & W14x283 \\
\hline & 2 & 5.55 & 191 & 16 & $\mathrm{~W} 24 \times 104$ & W14x283 \\
\hline & 3 & 3.91 & 703 & 20 & W30x173 & W14x283 \\
\hline \multirow[t]{3}{*}{ 3-1050-6B } & 1 & 5.85 & 245 & 16 & W24x117 & W14x211 \\
\hline & 2 & 3.95 & 178 & 12 & $\mathrm{~W} 24 \times 76$ & W14x211 \\
\hline & 3 & 3.25 & 658 & 16 & W30x148 & W14x211 \\
\hline \multirow[t]{5}{*}{ 9-1050-6B } & 1 & 15.19 & 867 & 34 & W33x291 & W36x800 \\
\hline & 2 & 13.97 & 859 & 30 & W30x235 & W36x800 \\
\hline & 5 & 10.62 & 534 & 20 & W30x148 & W36x361 \\
\hline & 8 & 7.33 & 178 & 12 & W24x103 & W36x247 \\
\hline & 9 & 6.04 & 907 & 26 & W30x173 & W36x247 \\
\hline \multirow[t]{5}{*}{$9-1050-8 \mathrm{~B}$} & 1 & 10.52 & 734 & 26 & W30x191 & W14x605 \\
\hline & 2 & 9.75 & 658 & 24 & W30x173 & W14x605 \\
\hline & 5 & 7.21 & 494 & 20 & W24x117 & $\mathrm{W} 14 \mathrm{x} 426$ \\
\hline & 8 & 5.63 & 663 & 10 & W24x117 & $\mathrm{W} 14 \mathrm{x} 283$ \\
\hline & 9 & 3.31 & 463 & 16 & W30x132 & $\mathrm{W} 14 \times 283$ \\
\hline \multirow[t]{5}{*}{$9-1050-10 \mathrm{~B}$} & 1 & 7.54 & 601 & 22 & W30x173 & W14x500 \\
\hline & 2 & 7.00 & 538 & 18 & W30x132 & W14x500 \\
\hline & 5 & 6.70 & 405 & 16 & $\mathrm{~W} 24 \times 117$ & W14x370 \\
\hline & 8 & 4.13 & 227 & 10 & W18x76 & $\mathrm{W} 14 \times 257$ \\
\hline & 9 & 3.36 & 596 & 16 & W30x132 & $\mathrm{W} 14 \times 257$ \\
\hline
\end{tabular}


Table 2: Weight savings for beam-only-connected web plate designs compared with fullyconnected web plate designs

\begin{tabular}{ccccc}
\hline Name & $\begin{array}{c}\text { HBE } \\
\text { savings (\%) }\end{array}$ & $\begin{array}{c}\text { Web plate } \\
\text { savings }(\%)\end{array}$ & $\begin{array}{c}\text { Approx. total } \\
\text { savings }(\%)\end{array}$ & savings (\%) \\
\hline $3-5050-6$ & -2.8 & 24.8 & -112 & 1.8 \\
$3-1050-4$ & 9.2 & 17.3 & -113 & 3.2 \\
$3-1050-6$ & 8.6 & 25.2 & -113 & 8.3 \\
$9-1050-6$ & 17.7 & 17.6 & -126 & 1.6 \\
$9-1050-8$ & 19.6 & 27.3 & -109 & 12 \\
$9-1050-10$ & 17.9 & 31.9 & -111 & 20 \\
\hline
\end{tabular}

Table 3: Ground motions selected for 9-story analyses

\begin{tabular}{cccc} 
Hazard Level & $50 / 50$ & $10 / 50$ & $2 / 50$ \\
\hline Ground & LA41 & LA01 & LA23 \\
Motions & LA42 & LA02 & LA24 \\
& LA43 & LA03 & LA25 \\
& LA44 & LA04 & LA26 \\
& LA51 & LA05 & LA31 \\
& LA52 & LA06 & LA32 \\
& LA53 & LA11 & LA33 \\
& LA54 & LA12 & LA34 \\
& LA55 & LA15 & LA35 \\
& LA56 & LA16 & LA36 \\
\hline
\end{tabular}


Table 4: Summarized median response parameters from nonlinear analyses

\begin{tabular}{|c|c|c|c|c|c|c|c|c|c|c|}
\hline \multirow[b]{2}{*}{ Model } & \multirow{2}{*}{$\begin{array}{c}\text { Response } \\
\text { Parameter }\end{array}$} & \multicolumn{3}{|c|}{$50 / 50$} & \multicolumn{3}{|c|}{$10 / 50$} & \multicolumn{3}{|c|}{$2 / 50$} \\
\hline & & $\mathrm{FC}$ & $\mathrm{BO}$ & $\mathrm{BO} / \mathrm{FC}$ & $\mathrm{FC}$ & $\mathrm{BO}$ & $\mathrm{BO} / \mathrm{FC}$ & $\mathrm{FC}$ & $\mathrm{BO}$ & $\mathrm{BO} / \mathrm{FC}$ \\
\hline \multirow[t]{4}{*}{$3-5050-6$} & $\theta_{s}$ & $0.10 \%$ & $0.60 \%$ & 6.00 & $0.18 \%$ & $0.47 \%$ & 2.61 & $0.34 \%$ & $1.11 \%$ & 3.26 \\
\hline & $\theta_{\text {resid }}$ & $0.015 \%$ & $0.004 \%$ & 0.27 & $0.021 \%$ & $0.020 \%$ & 0.95 & $0.037 \%$ & $0.056 \%$ & 1.51 \\
\hline & $D_{b}$ & 0.19 & 0.49 & 2.58 & 0.16 & 0.61 & 3.80 & 0.46 & 0.79 & 1.71 \\
\hline & $D_{c}$ & 0.33 & 0.36 & 1.09 & 0.14 & 0.38 & 2.71 & 0.40 & 0.59 & 1.48 \\
\hline \multirow[t]{4}{*}{$3-1050-4$} & $\theta_{s}$ & $0.29 \%$ & $0.51 \%$ & 1.76 & $0.98 \%$ & $2.27 \%$ & 2.32 & $3.52 \%$ & $5.40 \%$ & 1.53 \\
\hline & $\theta_{\text {resid }}$ & $0.017 \%$ & $0.010 \%$ & 0.59 & $0.12 \%$ & $0.071 \%$ & 0.59 & $0.17 \%$ & $0.42 \%$ & 2.47 \\
\hline & $D_{b}$ & 0.29 & 0.52 & 1.83 & 0.45 & 0.70 & 1.49 & 0.92 & 0.90 & 0.98 \\
\hline & $D_{c}$ & 0.51 & 0.27 & 0.76 & 0.58 & 0.65 & 1.12 & 0.86 & 1.00 & 1.16 \\
\hline \multirow[t]{4}{*}{$3-1050-6$} & $\theta_{s}$ & $0.45 \%$ & $0.46 \%$ & 1.02 & $1.06 \%$ & $1.71 \%$ & 1.61 & $2.99 \%$ & $4.82 \%$ & 1.61 \\
\hline & $\theta_{\text {resid }}$ & $0.13 \%$ & $0.009 \%$ & 0.07 & $0.14 \%$ & $0.055 \%$ & 0.39 & $0.49 \%$ & $0.25 \%$ & 0.51 \\
\hline & $D_{b}$ & 0.33 & 0.48 & 1.45 & 0.34 & 0.67 & 1.97 & 0.77 & 0.82 & 1.06 \\
\hline & $D_{c}$ & 0.33 & 0.23 & 0.70 & 0.34 & 0.53 & 1.56 & 0.73 & 0.96 & 1.32 \\
\hline \multirow[t]{4}{*}{$9-1050-6$} & $\theta_{s}$ & $0.58 \%$ & $0.67 \%$ & 1.16 & $0.89 \%$ & $0.94 \%$ & 1.06 & $2.23 \%$ & $2.63 \%$ & 1.18 \\
\hline & $\theta_{\text {resid }}$ & $0.008 \%$ & $0.008 \%$ & 1.00 & $0.070 \%$ & $0.024 \%$ & 0.34 & $0.411 \%$ & $0.100 \%$ & 0.24 \\
\hline & $D_{b}$ & 0.20 & 0.38 & 1.90 & 0.31 & 0.57 & 1.84 & 0.80 & 0.83 & 1.04 \\
\hline & $D_{c}$ & 0.37 & 0.42 & 1.14 & 0.62 & 0.66 & 1.06 & 1.00 & 1.00 & 1.00 \\
\hline \multirow[t]{4}{*}{$9-1050-8$} & $\theta_{s}$ & $0.37 \%$ & $0.88 \%$ & 2.37 & $0.49 \%$ & $0.98 \%$ & 2.00 & $2.76 \%$ & $3.25 \%$ & 1.18 \\
\hline & $\theta_{\text {resid }}$ & $0.018 \%$ & $0.024 \%$ & 1.33 & $0.050 \%$ & $0.108 \&$ & 2.16 & $0.213 \%$ & $0.334 \%$ & 1.57 \\
\hline & $D_{b}$ & 0.25 & 0.66 & 2.64 & 0.31 & 0.70 & 2.26 & 0.94 & 0.81 & 0.86 \\
\hline & $D_{c}$ & 0.23 & 0.74 & 3.22 & 0.45 & 0.69 & 1.53 & 0.85 & 1.01 & 1.19 \\
\hline \multirow[t]{4}{*}{$9-1050-10$} & $\theta_{s}$ & $0.46 \%$ & $0.62 \%$ & 1.35 & $0.67 \%$ & $0.90 \%$ & 1.34 & $2.35 \%$ & $3.08 \%$ & 1.31 \\
\hline & $\theta_{\text {resid }}$ & $0.014 \%$ & $0.267 \%$ & 19.1 & $0.026 \%$ & $0.146 \%$ & 5.62 & $0.312 \%$ & $0.212 \%$ & 0.68 \\
\hline & $D_{b}$ & 0.20 & 0.63 & 3.15 & 0.27 & 0.76 & 2.81 & 0.63 & 0.83 & 1.32 \\
\hline & $D_{c}$ & 0.15 & 0.76 & 5.07 & 0.39 & 0.75 & 1.92 & 0.62 & 0.966 & 1.55 \\
\hline
\end{tabular}


Figure 1: Schematic of forces in SC-SPSW with fully-connected web plates

Figure 2: Example of out-of-plane deformation along web plate corner cutout prior to web plate tearing

Figure 3: (a) Schematic of forces and (b) photo of test specimen for SC-SPSW with beamonly-connected web plates

Figure 4: Normalized PTF length vs. web plate aspect ratio

Figure 5: (a) Free-body diagram of intermediate beam under rightward lateral displacement with (b) beam flange PT force, (c) vertical web plate force, and (d) horizontal web plate force contributions

Figure 6: Moment distributions for (a) beam flange PT force, (b) vertical web plate force, and (c) horizontal web plate force contributions

Figure 7: (a) Axial force and (b) moment distributions beam with beam-only-connected web plates

Figure 8: Schematic of (a) single story SC-SPSW model with beam-only-connected web plates and (b) PT connection model

Figure 9: Calculated and Numerical axial force and moment distributions along beam in single-story SC-SPSW

Figure 10: Ratio of beam-only-connected to fully-connected web plate thicknesses vs. web plate aspect ratio

Figure 11: Comparison of experimental and numerical (Model TC) response of (a) fullyconnected and (b) beam-only-connected web plate specimens [adapted from Clayton et al. [4]]

Figure 12: Comparison of middle beam moment distribution calculated from equations, determined from numerical models (Model TO and Model TC), and determined from experimental strain gage readings.

Figure 13: Schematic of (a) fully-connected and (b) beam-only-connected SC-SPSW models 


\section{Figure Captions}

Figure 1: Schematic of forces in SC-SPSW with fully-connected web plates

Figure 2: Example of out-of-plane deformation along web plate corner cutout prior to web plate tearing

Figure 3: (a) Schematic of forces and (b) photo of test specimen for SC-SPSW with beam-only-connected web plates

Figure 4: Normalized PTF length vs. web plate aspect ratio

Figure 5: (a) Free-body diagram of intermediate beam under rightward lateral displacement with (b) beam flange PT force, (c) vertical web plate force, and (d) horizontal web plate force contributions

Figure 6: Moment distributions for (a) beam flange PT force, (b) vertical web plate force, and (c) horizontal web plate force contributions

Figure 7: (a) Axial force and (b) moment distributions beam with beam-only-connected web plates

Figure 8: Schematic of (a) single story SC-SPSW model with beam-only-connected web plates and (b) PT connection model

Figure 9: Calculated and Numerical axial force and moment distributions along beam in single-story SC-SPSW

Figure 10: Ratio of beam-only-connected to fully-connected web plate thicknesses vs. web plate aspect ratio

Figure 11: Comparison of experimental and numerical (Model TC) response of (a) fully-connected and (b) beam-only-connected web plate specimens [adapted from Clayton et al. [4]]

Figure 12: Comparison of middle beam moment distribution calculated from equations, determined from numerical models (Model TO and Model TC), and determined from experimental strain gage readings

Figure 13: Schematic of (a) fully-connected and (b) beam-only-connected SC-SPSW models 


\section{Table Captions}

Table 1: Design parameters for prototype SC-SPSWs with beam-only-connected web plate designs

Table 2: Weight savings for beam-only-connected web plate designs compared with fully-connected web plate designs

Table 3: Ground motions selected for 9-story analyses

Table 4: Summarized median response parameters from nonlinear analyses 


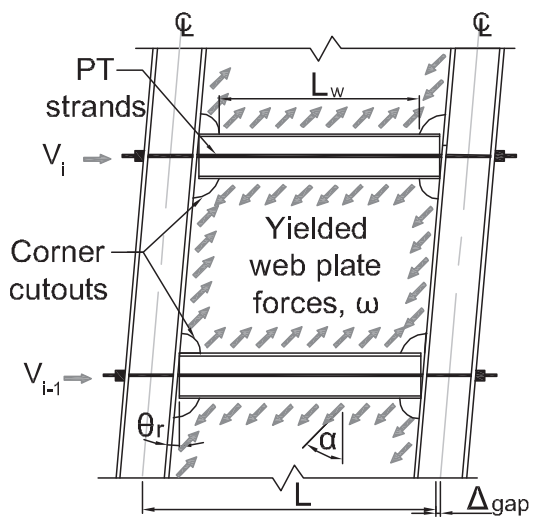

Figure 1: Schematic of forces in SC-SPSW with fully-connected web plates

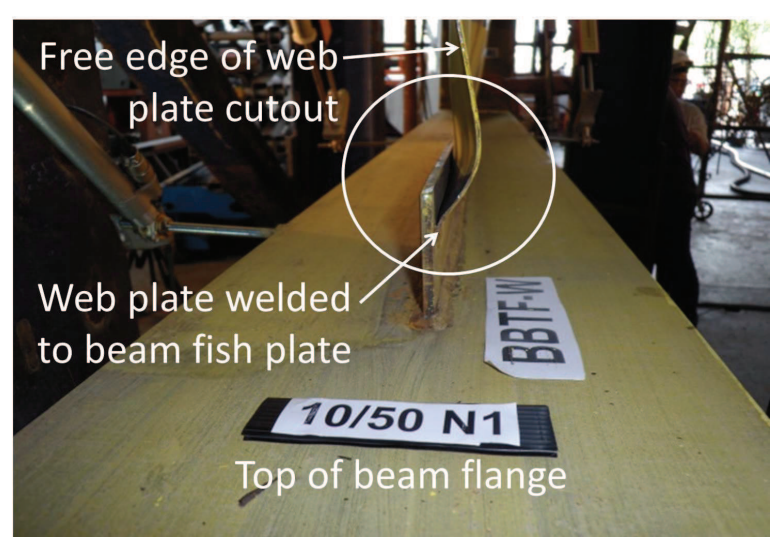

Figure 2: Example of out-of-plane deformation along web plate corner cutout prior to web plate tearing 


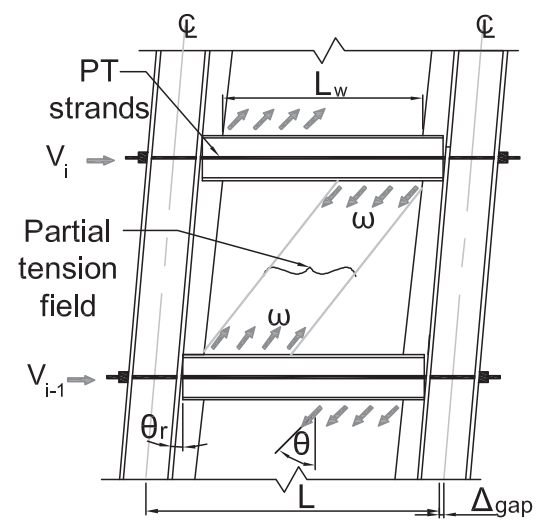

(a)

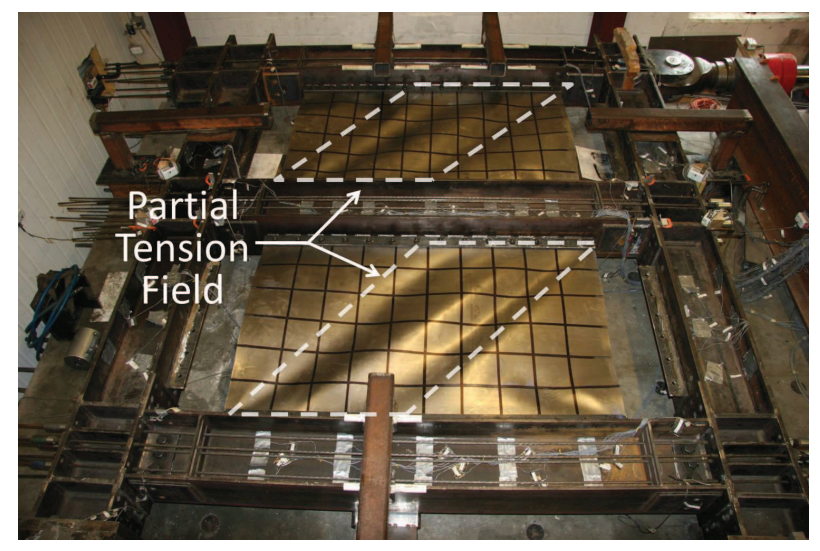

(b)

Figure 3: (a) Schematic of forces and (b) photo of test specimen for SC-SPSW with beamonly-connected web plates 


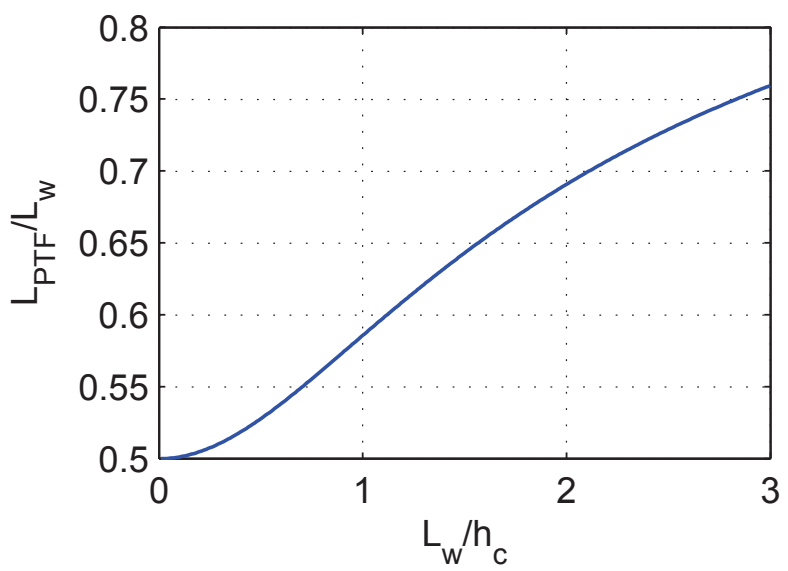

Figure 4: Normalized PTF length vs. web plate aspect ratio 
(a)

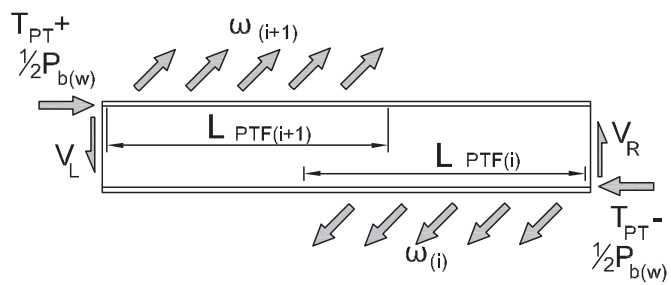

(b)

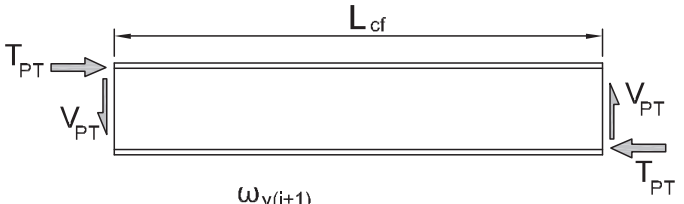

(c)

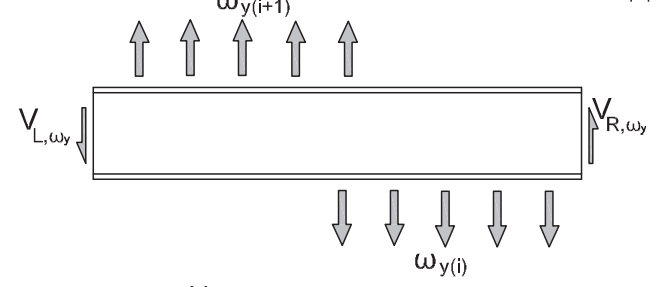

(d)

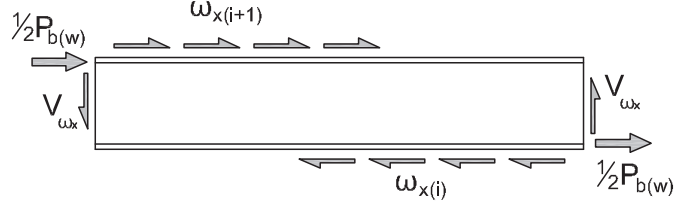

Figure 5: (a) Free-body diagram of intermediate beam under rightward lateral displacement with (b) beam flange PT force, (c) vertical web plate force, and (d) horizontal web plate force contributions 


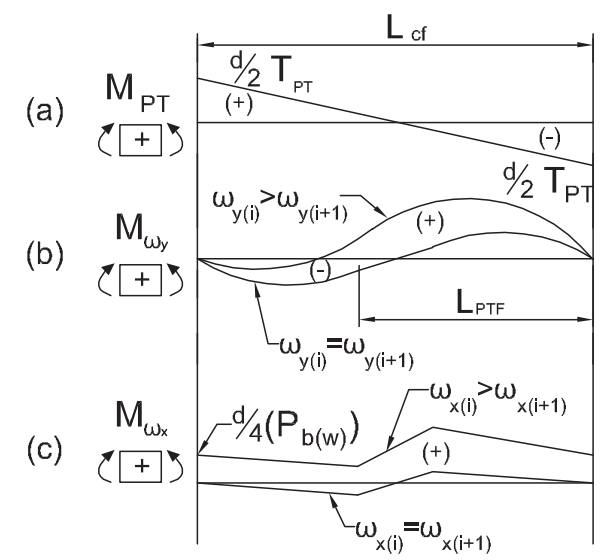

Figure 6: Moment distributions for (a) beam flange PT force, (b) vertical web plate force, and (c) horizontal web plate force contributions

(a)

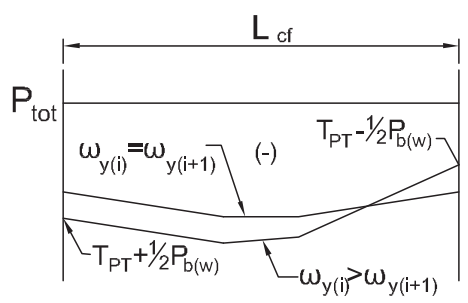

(b)

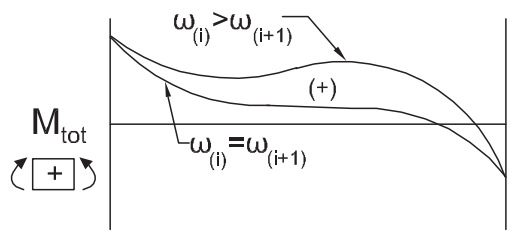

Figure 7: (a) Axial force and (b) moment distributions beam with beam-only-connected web plates 


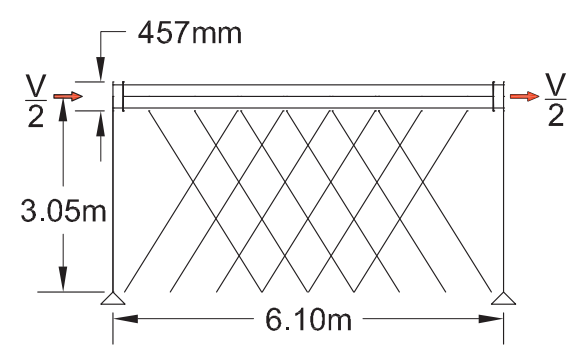

(a)

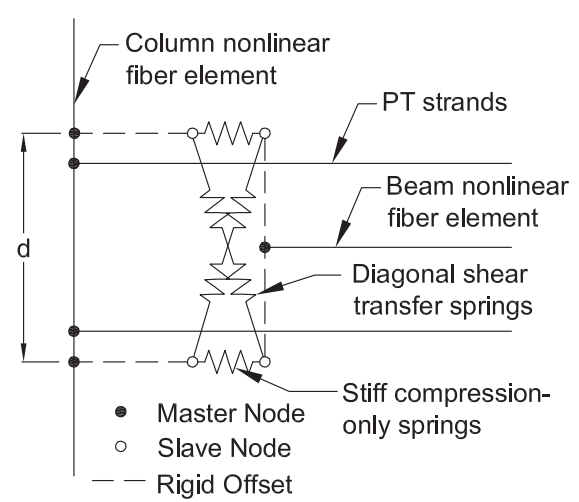

(b)

Figure 8: Schematic of (a) single story SC-SPSW model with beam-only-connected web plates and (b) PT connection model 


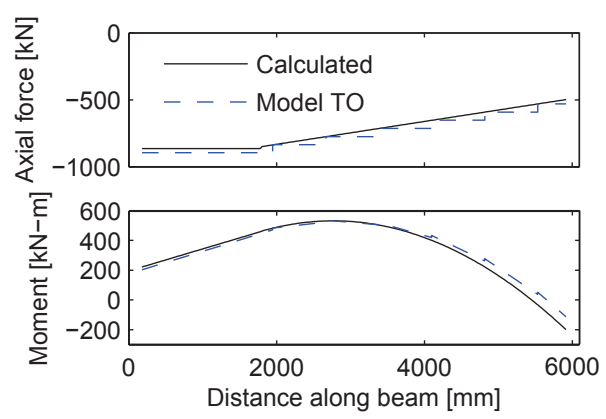

Figure 9: Calculated and Numerical axial force and moment distributions along beam in single-story SC-SPSW

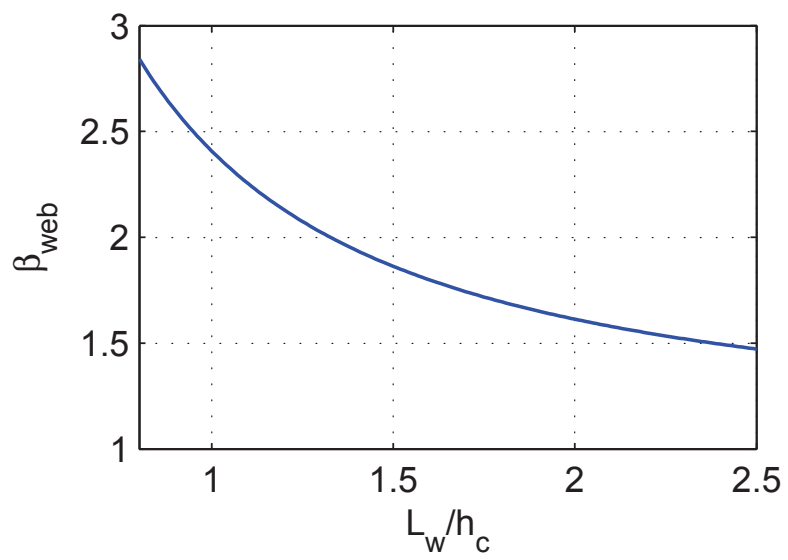

Figure 10: Ratio of beam-only-connected to fully-connected web plate thicknesses vs. web plate aspect ratio 


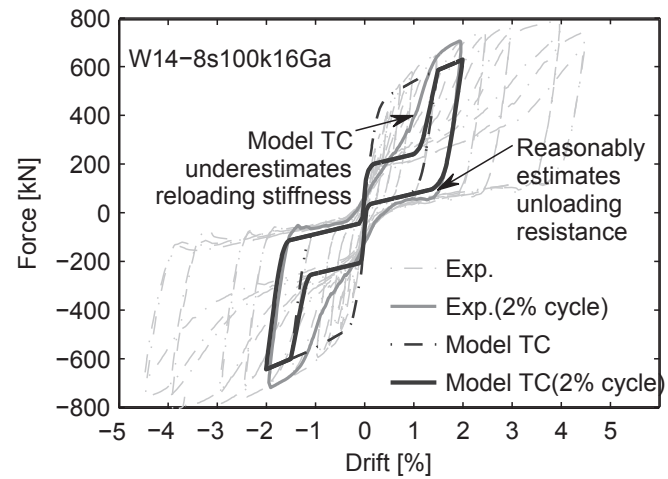

(a)

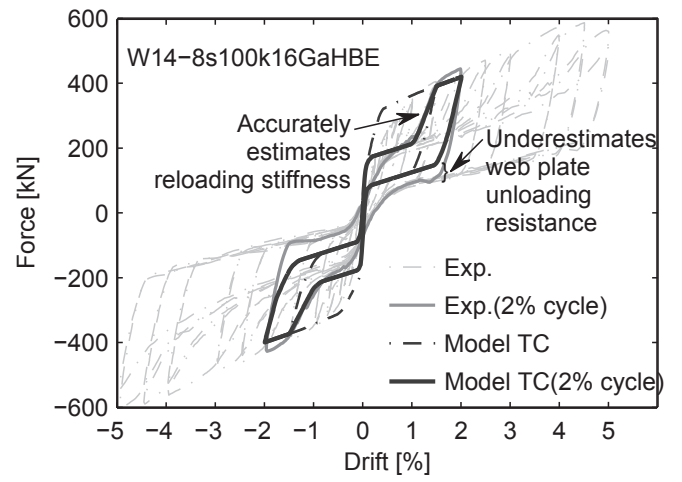

(b)

Figure 11: Comparison of experimental and numerical (Model TC) response of (a) fullyconnected and (b) beam-only-connected web plate specimens [adapted from Clayton et al. [4]] 


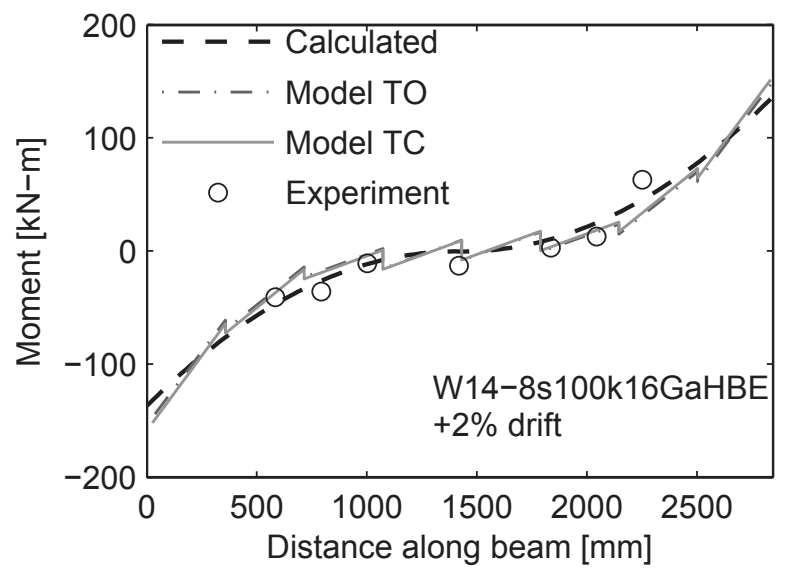

Figure 12: Comparison of middle beam moment distribution calculated from equations, determined from numerical models (Model TO and Model TC), and determined from experimental strain gage readings.

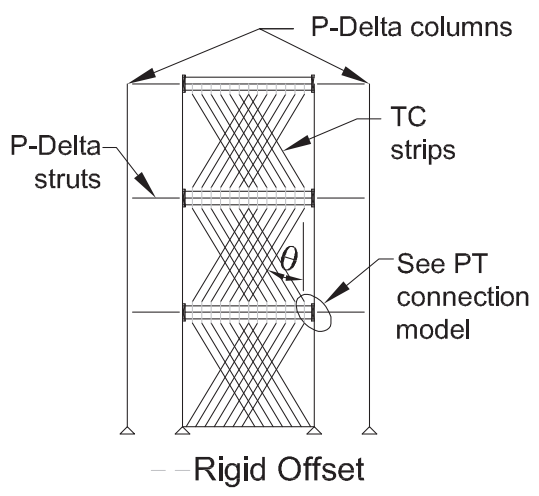

(a)

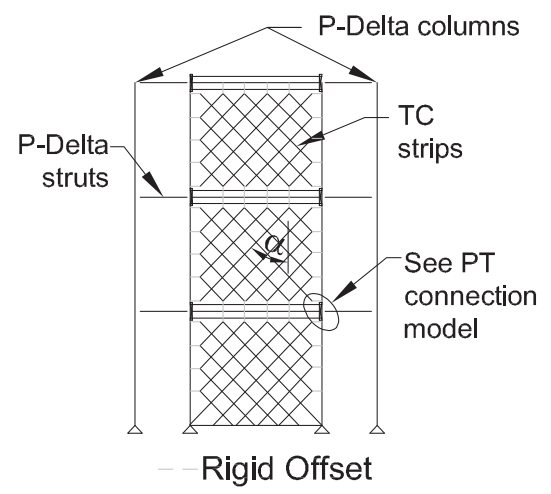

(b)

Figure 13: Schematic of (a) fully-connected and (b) beam-only-connected SC-SPSW models 